Noticias

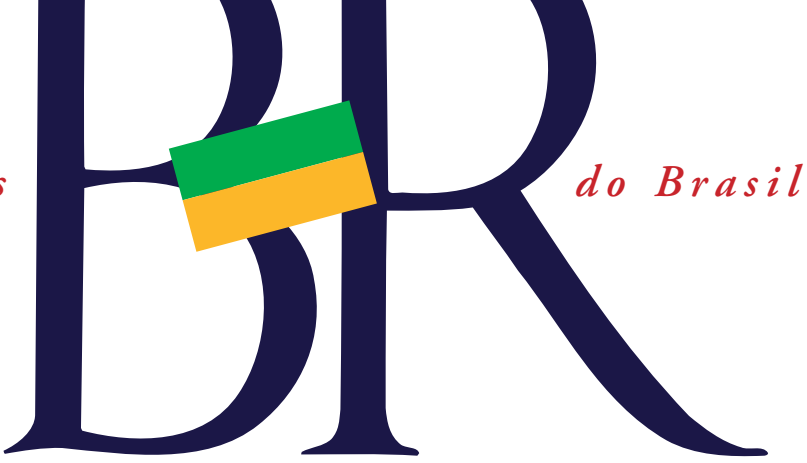

SAÚdE

\section{Novas abordagens para esquizofrenia}

A morte recente do cineasta e documentarista Eduardo Coutinho trouxe à tona os problemas enfrentados pelos portadores da esquizofrenia e suas famílias. Coutinho e sua mulher foram esfaqueados durante um surto do filho Daniel, que tem a doença. Uma das principais características da doença é a perda do contato com a realidade. "Depois de um século estudando a esquizofrenia, as causas desse distúrbio permanecem desconhecidas. Vários tratamentos, especialmente os farmacológicos, têm sido amplamente usados durante cerca de meio século e ainda não existem evidências de que tenham trazido melhoras substanciais para a maioria das pessoas com esquizofrenia", afirmou o psiquiatra Thomas R. Insel, diretor do Instituto Nacional de Saúde Mental, nos Estados Unidos, em artigo publicado em 2010, na revista Nature.

Os primeiros sintomas desse distúrbio mental surgem, em geral, durante a transição da adolescência para a fase adulta, quando o córtex pré-frontal está em processo final de amadurecimento e os circuitos neurais ainda buscam um equilíbrio. No artigo de 2010, o psiquiatra norte-americano já destacava ser

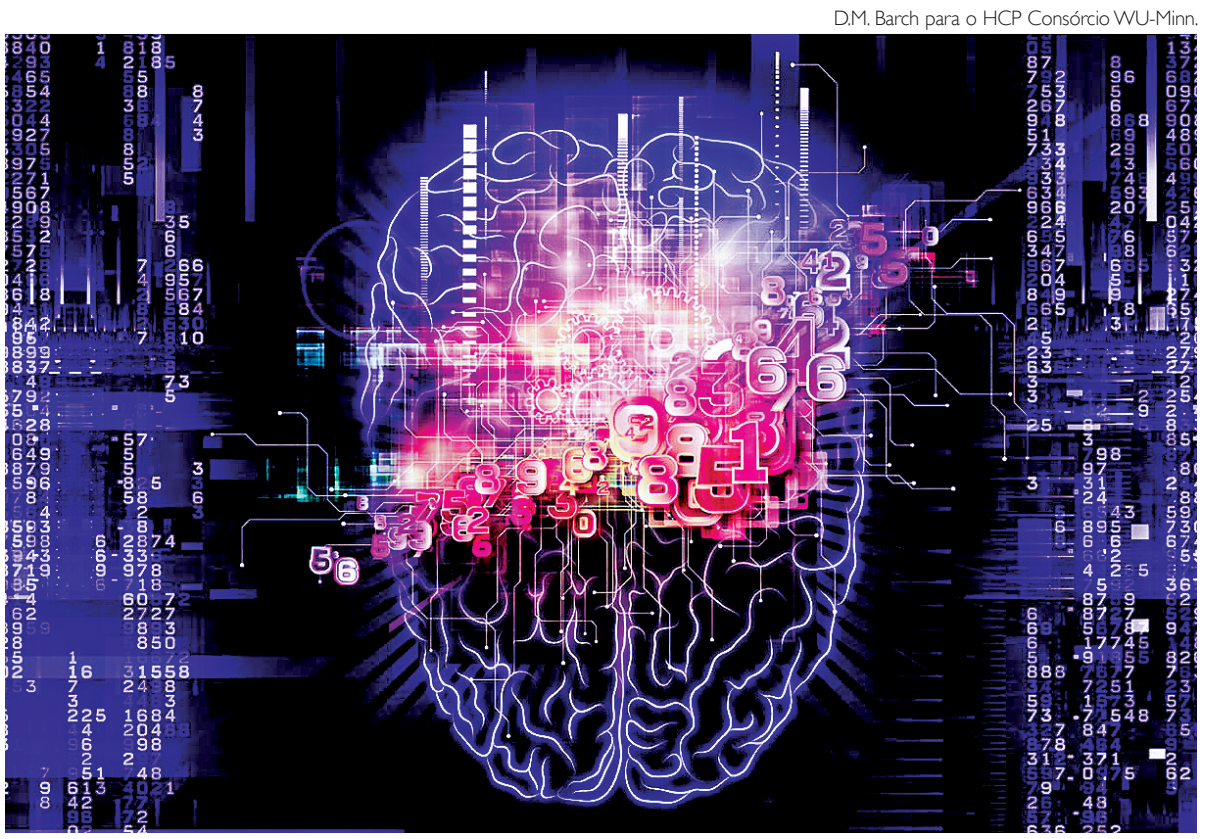

Divulgação do projeto Brain Iniciative

preciso investir em pesquisas que desvendassem a complexidade das estruturas e dos circuitos cerebrais, em busca de respostas sobre as causas da esquizofrenia e os caminhos efetivos de seu tratamento. Insel define a esquizofrenia como uma desordem do desenvolvimento neurológico - o que, segundo ele, além de ser "profundamente diferente da maneira como se via essa doença no século passado", significaria "uma nova esperança para a sua prevenção e cura nas próximas duas décadas". Sinais desse novo olhar sobre a doença já são notados desde 2009, quando o Instituto Nacional de Saúde Mental dos EUA lançou o programa Research Domain Cri- teria (RDoc), com o objetivo de desvendar as dimensões básicas do funcionamento cerebral, como os circuitos de memórias, emoções e medo. A ideia era vasculhar desde os genes às conexões neuronais, passando pelas substâncias neurotransmissoras envolvidas nas sinapses para entender melhor algumas psicopatologias e, assim, oferecer uma assistência integral aos pacientes. Essa tendência ganhou força em 2013, quando o presidente Barack Obama anunciou o projeto Breakthrough Research And Innovation in Neurotechnology (Brain, na sigla em inglês para pesquisa de ponta e inovação em neurotecnologia). A iniciativa - que vem sen- 
Noticias

do considerada ambiciosa pela sua abrangência -, promete mapear a atividade cerebral nos próximos 10 anos com novidades sobre seus princípios de funcionamento. A ideia é descobrir como as células cerebrais interagem, usando tecnologias que produzam "imagens dinâmicas" do cérebro. O projeto está sendo desenvolvido de forma conjunta por vários institutos de pesquisa públicos e privados nos EUA, com uma previsão de investimento de US\$ 10 bilhões.

SINTOMAS DA SÍNDROME Considerando a dimensão dos prejuízos advindos de uma doença como a esquizofrenia, todos os esforços se justificam. A esquizofrenia atinge - na maioria das vezes de maneira devastadora -, cerca de $1 \%$ da população ou 70 milhões de pessoas ao redor do mundo, segundo dados da Organização Mundial de Saúde (OMS). Classificada hoje pela psiquiatria como uma síndrome, ela é caracterizada por uma série de sintomas e sinais que costumam surgir pela primeira vez, na forma de um surto psicótico, por volta dos 20 anos, nos homens, e 25, nas mulheres. Os portadores apresentam um conjunto de "sintomas positivos", como alucinaçôes, delírios e desorganização do pensamento, durante as crises agudas, intercalados por períodos de remissão. A doença é acompanhada também pelos cha- mados "sintomas negativos": dificuldade de expressão das emoçôes, apatia, isolamento social e um sentimento profundo de desesperança, que acentua tendências ao suicídio. O portador de esquizofrenia apresenta ainda problemas cognitivos, tais como dificuldade de abstração, déficit de memória, comprometimento da linguagem e falhas no aprendizado. A combinação desses sintomas causa grande sofrimento psíquico, com prejuízos nas relaçôes familiares e na vida profissional e demais relações sociais dos portadores da síndrome. Ao mesmo tempo, a cura, é uma esperança para poucos: estudos realizados nos Estados Unidos mostraram que menos que $14 \%$ dos portadores podem ser considerados curados cinco anos após o primeiro surto psicótico, período considerado crítico para o desfecho da doença.

ASSISTÊNCIA PREVENTIVA Com base nessas pesquisas, programas de prevenção voltados para o paciente de primeiro surto foram surgindo em vários países. No Brasil, o programa pioneiro de pesquisa e atendimento ao Primeiro Episódio Psicótico (PEP) foi criado em 1999, pelo grupo da psiquiatra Ana Cristina Chaves, do Departamento de Psiquiatria da Universidade Federal de São Paulo (Unifesp). O programa promove encontros de grupos de pacientes e familiares, que trocam experiências sobre uso de medicação, sintomas, reinserção social e no mercado de trabalho. "A troca de informaçōes entre as pessoas envolvidas com a doença ou entre o próprio doente e seus pares é muito importante", diz Chaves, lembrando que os participantes desses grupos sabem mais do dia a dia da doença do que os profissionais do serviço. Segundo ela, os temas mais discutidos são a manutenção da medicação e a "volta ao mundo", passada a crise. "A psicose, de maneira geral, não só a esquizofrenia, deveria ser tratada institucionalmente, por meio de serviços de assistência que permitem compartilhar experiências e oferecem suporte ao tratamento", afirma a psiquiatra da Unifesp.

NOVAS HIPÓTESES TERAPÊUTICAS As drogas antipsicóticas, que integram a primeira linha de tratamento para os indivíduos com esquizofrenia e outras doenças mentais relacionadas, podem causar sérios efeitos colaterais, tais como desordens do metabolismo, ganho de peso e cardiopatias. Por conta desses efeitos, muitos pacientes abandonam a medicação, o que motiva, atualmente, a pesquisa para encontrar novas drogas. "As medicaçôes usadas como antipsicóticos até agora agem bloqueando alguns tipos de receptores de dopamina", explica o psiquiatra Jaime Hallak, professor da Faculdade de Medicina de Ribeirão 


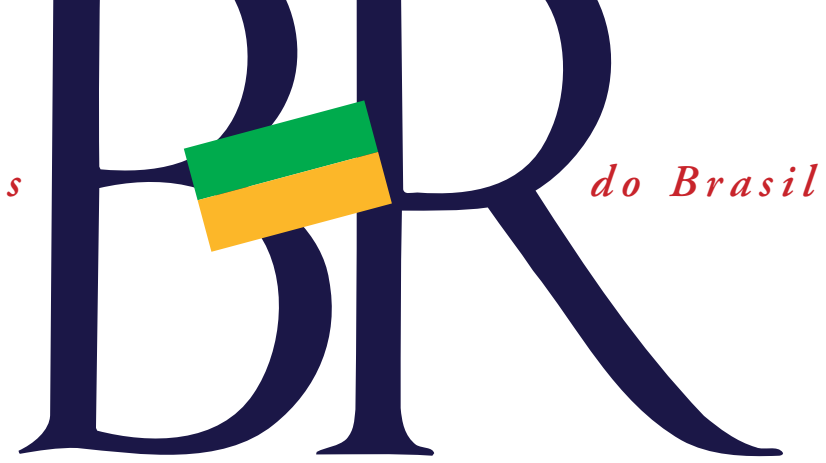

Preto, da Universidade de São Paulo (USP). Ele lidera um estudo que tem uma nova abordagem farmacológica para o tratamento de síndromes como a esquizofrenia. Hallak e sua equipe se debruçaram sobre os receptores de glutamina. "Já se sabe que o receptor glutamatérgico tem sua ação diminuída na esquizofrenia”, explica. Ainda de acordo com ele, a ativação desse receptor desencadeia a produção de óxido nítrico, substância responsável por modular a comunicação entre as células nervosas. "Se esse mecanismo for prejudicado, o sistema nervoso passa a reagir de maneira disfuncional e pode provocar alteraçōes comportamentais, como as que aparecem na esquizofrenia", diz o pesquisador.

O estudo do grupo de Ribeirão Preto foi realizado em parceria com pesquisadores da Universidade de Alberta, no Canadá, e publicado no Jama Psychiatry (maio, 2013). Para aumentar os níveis de óxido nítrico e controlar os sintomas psi-

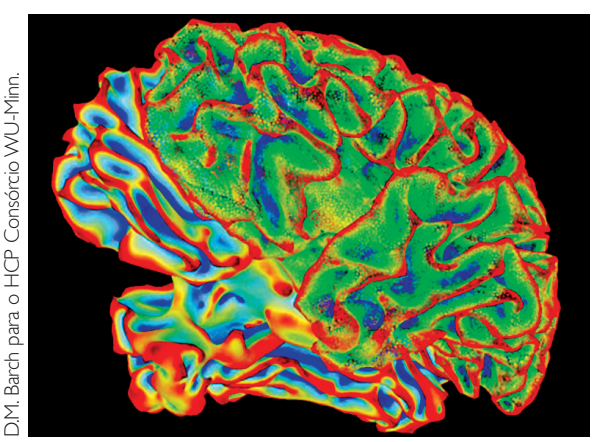

Imagem de um cérebro gerada por tomografia cóticos, os pesquisadores testaram o uso do nitroprussiato de sódio, um medicamento antigo, usado desde 1893 para tratar a hipertensão arterial sistêmica. A substância foi administrada em ambiente hospitalar, por via intravenosa, com resultados positivos, tais como a melhoria do funcionamento do sistema nervoso central e a redução dos sintomas de alucinação.

CÉLULAS-TRONCO Outra linha de pesquisa que tem se mostrado promissora para entender a esquizofrenia e desenvolver novos tratamentos é a reprogramação de células-tronco. Utilizando células-tronco de pluripotência induzida, fabricadas a partir de amostras celulares de pacientes com esquizofrenia, o biomédico Stevens Rehen, do Laboratório Nacional de Células-Tronco Embrionárias, da Universidade Federal do Rio de Janeiro (UFRJ), descobriu que células de portadores de esquizofrenia consomem duas vezes mais oxigênio do que as de não portadores do transtorno. A partir dessa descoberta, Rehen e sua equipe conseguiram "reparar" os neurônios in vitro, por meio da administração de ácido valproico. O grupo foi o primeiro no mundo a fazer a reversão das marcas bioquímicas de neurônios humanos com esquizofrenia em laboratório.

Alice Giraldi e Silvia Campolim

\section{MEDICINA}

Lesão medular: para além do chute da copa

“Você já andou hoje?", essa é uma das perguntas que mais se ouve no Laboratório de Biomecânica e Reabilitação do Aparelho Locomotor, do Hospital das Clínicas da Universidade Estadual de Campinas (Unicamp). A frequência do questionamento não causaria espanto se a sala, quase escondida ao fim do longo corredor, não fosse o local de tratamento de pacientes com lesão medular.

Lá, cem cadeirantes recebem tratamento com eletroestimulação neuronal, técnica que consiste em ligar eletrodos que transmitem pequenos choques ao músculo paralisado, provocando contração muscular. A partir desses estímulos, "eles apresentam movimentos involuntários e depois, de forma ainda não completamente compreendida, é reestabelecida a conexão com o cérebro", explica Alberto Cliquet Júnior, professor do Departamento de Ortopedia e Traumatologia da Faculdade de Ciências Médicas da Unicamp e do Departamento de Engenharia Eletrônica da Universidade de São Paulo (USP). 